\title{
Pharmacokinetic-pharmacodynamic modelling of atazanavir in hair among adolescents on antiretroviral treatment in Zimbabwe
}

Bernard Ngara $^{1 *} \mathbb{D}$, Simbarashe Zvada ${ }^{2}$, Tariro Dianah Chawana ${ }^{3}$, Charles Fungai Brian Nhachi $^{3}$ and Simbarashe Rusakaniko

\begin{abstract}
Background: Drug potency is a pharmacological parameter defining dose or concentration of drug required to obtain 50\% of the drug's maximal effect. Pharmacokinetic-pharmacodynamic modelling and simulation allows estimation of potency and evaluate strategies improving treatment outcome. The objective of our study is to determine potency of atazanavir in hair, defined as atazanavir level in hair associated with 50\% probability of failing to achieve viral load below 1000 copies/ml among adolescents, and explore the effect of participant specific variables on potency.

Methods: A secondary analysis was performed on data from a previous study conducted in HIV-infected adolescents failing 2nd line ART from Harare central hospital, Zimbabwe, between 2015 and 2016. We simulated atazanavir concentrations in hair using NONMEM (version 7.3) ADVAN 13, based on a previously established pharmacokinetic model. Logistic regression methods were used for PKPD analysis. Simulations utilising PKPD model focused on estimation of potency and exploring the effect of covariates.

Results: The potency of atazanavir in hair was found to be $4.5 \mathrm{ng} / \mathrm{mg}$ hair before adjusting for covariate effects. Participants at three months follow-up, reporting adequate adherence, having normal BMI-for-age, and cared for by mature guardians had increased potency of atazanavir in hair of $2.6 \mathrm{ng} / \mathrm{mg}$, however the follow-up event was the only statistically significant factor at $5 \%$ level.

Conclusion: Atazanavir in hair in the range 2.6 to $4.5 \mathrm{ng} / \mathrm{mg}$ is associated with above $50 \%$ probability of early viral load suppression. Adherence monitoring to adolescents with lower potency of atazanavir is recommended. The effect self-reported adherence level, BMI-for-age, and caregiver status require further evaluation.
\end{abstract}

Keywords: Pharmacodynamics, Pharmacokinetics, Modelling, HIV, Adolescents, Hair

\footnotetext{
* Correspondence: bernardngara4@gmail.com

'Department of Community Medicine, University of Zimbabwe College of Health Sciences, Mazowe Street, Parirenyatwa Complex, P. O Box A178 Avondale, Harare, Zimbabwe

Full list of author information is available at the end of the article
}

(C) The Author(s). 2021 Open Access This article is licensed under a Creative Commons Attribution 4.0 International License, which permits use, sharing, adaptation, distribution and reproduction in any medium or format, as long as you give appropriate credit to the original author(s) and the source, provide a link to the Creative Commons licence, and indicate if changes were made. The images or other third party material in this article are included in the article's Creative Commons licence, unless indicated otherwise in a credit line to the material. If material is not included in the article's Creative Commons licence and your intended use is not permitted by statutory regulation or exceeds the permitted use, you will need to obtain permission directly from the copyright holder. To view a copy of this licence, visit http://creativecommons.org/licenses/by/4.0/ The Creative Commons Public Domain Dedication waiver (http://creativecommons.org/publicdomain/zero/1.0/) applies to the data made available in this article, unless otherwise stated in a credit line to the data. 


\section{Background}

The application of exposure-response analysis remains very crucial in testing drug research or development strategies in all phases. The exposure may be the dose or a relevant pharmacokinetic (PK) measure such as drug concentration. The response is referred to as the pharmacodynamic (PD) outcome. If the exposure being used is derived from a PK model, such exposure-response analysis is also referred as PKPD modelling. Drug potency is the dose or concentration of a drug required to get $50 \%$ of that drug's maximal effect, expressing the intensity of drug activity. A drug that causes a response to occur at a lower concentration has higher potency and is desirable compared to a drug causing the same response at a higher concentration [1].

Several models for exposure-response analysis estimate potency using simple to more complex modelling. Logistic regression is among the common methods used for PKPD modelling of binary response. This approach has been tested and advocated for use with the primary focus of determining the effective concentration corresponding to $x$-percent response $\left(E C_{x}\right)$ [2-7]. Although some findings show that the accuracy of $E C_{x}$ estimates is questionable, the use of the logit model remains one of the robust methods to estimate the $E C_{x}$ values and allows comparison of these values for different strategies being tested [8-10].

The effective concentration relating to concentrations that cause $50 \%$ of the maximum effect $\left(E C_{50}\right)$ defines the concentration at which the curvature of the response line occurs. The $E C_{50}$ is a derived quantity estimated robustly, less dependent on the model accuracy, and is also a commonly used quantitative pharmacodynamic parameter in testing the potency of drug treatment strategy [11-16]. Additional parameters, such as $E C_{80}$ or $E C_{90}$ relating to concentrations that cause 80 and $90 \%$, respectively, of the maximum effect are however also useful, but they highly depend on model accuracy [17].

Several studies showed that antiretroviral drug concentrations in hair predict virologic treatment outcome accurately. Some of these studies estimated antiretroviral concentrations in hair and thresholds associated with failing to suppress viral load derived using approaches which cannot meet the minimal acceptable standards of PKPD modelling [18-20]. The PKPD modelling approaches allow performance of simulation-based estimations and to derive strategies that optimize treatment outcome. Therefore, in this article, the aim is to establish a reference range for atazanavir concentration in hair associated with higher probability of failing to achieve viral load below 1000 copies/ml (i.e. potency) in adolescents for clinical practice. In doing so, the objective is to fit a PKPD model of the relationship between viral load and PK model-based simulated atazanavir concentration in hair, determine atazanavir in hair which corresponds to 50, 80 and $90 \%$ probabilities of treatment success, and additionally to explore the participant specific variables associated with a decrease in the $\mathrm{EC}_{50}$ value.

\section{Method}

\section{Data source}

Secondary analysis of data from a randomized clinical trial comprising 50 adolescents on atazanavir/ritonavirbased 2nd line antiretroviral therapy (ART) for at least 6 months was performed. In the primary study, participants were randomised to either modified directly administered antiretroviral therapy arm (intervention) or standard of care arm (control) and followed-up for 3 months. Informed consent questionnaires were used. Viral load and hair samples were collected at baseline and after 3 months follow-up [18]. Atazanavir concentrations in hair were determined using the liquid chromatography/mass spectrometry/mass spectrometry, with an assay range of $0.05-20 \mathrm{ng} / \mathrm{mg}$. The trial is registered with the Pan African Clinical Trial Registry (PACT R201502001028169) and NIH Clinical Trials.gov (NCT02689895). The trial obtained ethical approval from local institutions which include the Joint Research Ethics Committee (JREC/51/14) and Medical Research Council of Zimbabwe (MRCZ/A/1840). Steady-state atazanavir concentrations in hair were simulated based previously established population PK model [21]. The PD outcome was the actual measured viral load dichotomised as below or above $<1000$ copies/ml at three months follow-up. In this study, we maintained covariate effects that were significant in the population PK model.

\section{PKPD modelling}

Simple logistic regression was used to fit a relationship between viral load below 1000 copies/ml and the simulated atazanavir concentration in hair as the baseline PKPD model. The probability of treatment failure (viral load $\geq 1000$ copies $/ \mathrm{ml}$ ) for a given a hair concentration $\left(\mathrm{X}_{1}\right)$ was estimated using the "predict" function in Rstatistical package which applies to eq. 1 , where $\beta_{0}$ is the estimated regression constant, and $\beta_{1}$ is the estimated regression coefficient for the $X_{1}$ variable.

$$
\text { Probability (Failure } \left.\mid X_{1}\right)=\frac{e^{\left[\beta_{0}+\beta_{1} X_{1}\right]}}{1+e^{\left[\beta_{0}+\beta_{1} X_{1}\right]}}
$$

We performed multivariate logistic regression to adjust for covariate effects on the relationship between viral load below 1000 copies $/ \mathrm{ml}$ and the simulated atazanavir concentration in hair as the covariate PKPD model. Self-reported adherence, age-adjusted body mass index (BMI-for-age), the study follow-up event, and participant caregiver status were considered for testing 
based on contribution to the variability of atazanavir in hair reported earlier [18, 21]. Covariates were included in the full model if they exhibited the potential to decrease the $E C_{50}$ value.

The probability of treatment failure was estimated for given: hair concentration level $\left(X_{1}\right)$, self-reported adherence measured by visual analogue scale (VAS) $\left(X_{2}\right)$, BMI-for-age $\left(X_{3}\right)$ categorised in three groups as underweight ( $<5$ th percentile), normal (5th to $<95$ th percentile) and underweight ( $\geq 95$ th percentile), follow-up event $\left(X_{4}\right)$, and participant caregiver status $\left(X_{5}\right)$ using the "predict" function in R-statistical package which apply eq. 2 , where $\beta_{0}$ is the estimated regression constant, $\beta_{1}, \beta_{2}, \beta_{3}$, $\beta_{4}$ and $\beta_{5}$ are the estimated regression coefficients for $\mathrm{X}_{1}, \mathrm{X}_{2}, \mathrm{X}_{3}, \mathrm{X}_{4}$ and $\mathrm{X}_{5}$ variables, respectively:

$$
\mathrm{P}\left(\text { Failure } \mid \mathrm{X}_{1} ; \mathrm{X}_{2} ; \mathrm{X}_{3} ; \mathrm{X}_{4} ; \mathrm{X}_{5}\right)=\frac{\mathrm{e}^{\left[\beta_{0}+\beta_{1} \mathrm{X}_{1}+\beta_{2} \mathrm{X}_{2}+\beta_{3} \mathrm{X}_{3}+\beta_{4} \mathrm{X}_{4}+\beta_{5} \mathrm{X}_{5}\right]}}{1+\mathrm{e}^{\left[\beta_{0}+\beta_{1} \mathrm{X}_{1}+\beta_{2} \mathrm{X}_{2}+\beta_{3} \mathrm{X}_{3}+\beta_{4} \mathrm{X}_{4}+\beta_{5} \mathrm{X}_{5}\right]}}
$$

Statistical significance of the covariates included in the final model and comparison of accuracy among hierarchical models were tested using analysis of variance (ANOVA) at 5\% level of significance as part of model validation. Multicollinearity of the covariates included was checked using the mean variance inflation factor (VIF) value of less than 10 and there was no any relationship observed.

\section{Simulation and determination of $E C_{x}$ values}

We simulated the relationship between viral load and atazanavir concentration in hair while adjusting for individual covariate effects. The participant specific variables that had a potential of decreasing the $E C_{50}$ value were used in simulation of the full covariate PKPD model. Simulations were performed using the using the "predict" function in R-statistical package. Plot diagrams of simulated concentration versus probability of treatment failure including 95\% confidence interval (CI) represented by shaded areas were constructed using the "ggplot2" functions in R-statistical package. Graphical interpolation was performed on the plots to determine baseline $E C_{x}$ values and also to present the effect of individual and multiple covariates on the $E C_{50}$ value.

\section{Results}

\section{Description of study data}

The mean age was 15.8 years (standard deviation - 1.8) and $54 \%$ were females. In terms of education, $89 \%$ had completed secondary school, 9\% completed primary school and 2 were dropouts. About 54\% had normal BMI, $15 \%$ were overweight while $30 \%$ were underweight. Regards to caregivers, 20\% were biological parents, $40 \%$ were grandparents, $10 \%$ were siblings and $30 \%$ were aunt or uncle. About $32 \%$ were in the early $\mathrm{WHO}$ disease progression stage at ART initiation, while $68 \%$ were of the late stage. The mean adherence by visual analogue scale (VAS) score was $84.2 \%$ (standard deviation - 18.1). The median length of hair was $1 \mathrm{~cm}$ (range $-0.5 \mathrm{~cm}$ to $1.5 \mathrm{~cm}$ ). The mean hair weight was $2 \mathrm{mg}$ (standard deviation - 0.15). Most of the study participants estimated to be $82 \%$ were on tenofovir/lamivudine/atazanavir/ritonavir drug combination. The mean ( $95 \%$ confidence interval) simulated atazanavir concentration in hair was $1.2(0.8-1.6) \mathrm{ng} / \mathrm{mg}$ hair and $2.2(1.5-2.8) \mathrm{ng} / \mathrm{mg}$ hair at enrolment and follow-up, respectively. The median (interquartile range) of observed viral load was 70,676 $(21,862$ to 164,800$)$ copies/ml and $8141(<40$ to 82,250$)$ copies $/ \mathrm{ml}$ at enrolment and follow-up, respectively. All participants were adolescents with virologic treatment failure (viral load $\geq 1000$ copies $/ \mathrm{ml}$ ) to atazanavir-based 2nd line ART at enrolment. About $40 \%$ of the study participants became virologically suppressed (viral load $<1000$ copies/ml) after follow-up.

\section{Baseline $E C_{50}, E C_{80}$ and $E C_{90}$ values}

The $E C_{50}$ of atazanavir in hair was estimated to be $4.5 \mathrm{ng} / \mathrm{mg}$ hair with a $95 \%$ confidence interval of 3.5 to $7.6 \mathrm{ng} / \mathrm{mg}$ hair. The $E C_{80}$ was estimated to be 6.5 $\mathrm{ng} / \mathrm{mg}$ and a right-tailed $95 \%$ confidence interval with a lower limit of $4.9 \mathrm{ng} / \mathrm{mg}$ hair, while the $E C_{90}$ was estimated to be $7.8 \mathrm{ng} / \mathrm{mg}$ hair and a right-tailed $95 \%$ confidence interval with a lower limit of $7.8 \mathrm{ng} / \mathrm{mg}$ hair. Figure 1 illustrates further the relationship between probability of failing to achieve viral load below 1000 copies $/ \mathrm{ml}$ and the simulated atazanavir concentrations in hair.

\section{Effect of self-reported adherence on $E C_{50}$ value}

The average $E C_{50}$ for a participant with $100 \%$ selfreported adherence was estimated to be approximately equal to $4.5 \mathrm{ng} / \mathrm{mg}$ hair and a $95 \%$ confidence interval of 3.5 to $7.6 \mathrm{ng} / \mathrm{mg}$ hair. The average $E C_{50}$ for a participant with $50 \%$ self-reported adherence was estimated to be approximately equal to $4.4 \mathrm{ng} / \mathrm{mg}$ hair and a right-tailed $95 \%$ confidence interval with a lower limit of $1.8 \mathrm{ng} / \mathrm{mg}$ hair. The effect of $50 \%$ self-reported adherence on the relationship between viral load and the simulated atazanavir concentrations in hair is illustrated further in Fig. 2.

\section{Effect of $\mathrm{BMI}$-for-age on $E C_{50}$ value}

The average $E C_{50}$ for normal BMI-for-age participants was estimated to be approximately $3.8 \mathrm{ng} / \mathrm{mg}$ hair and a $95 \%$ confidence interval of 2.7 to $6.8 \mathrm{ng} / \mathrm{mg}$ hair compared to that for participants with normal BMIfor-age. The average $E C_{50}$ for overweight participants was estimated to be approximately $3.5 \mathrm{ng} / \mathrm{mg}$ hair and 


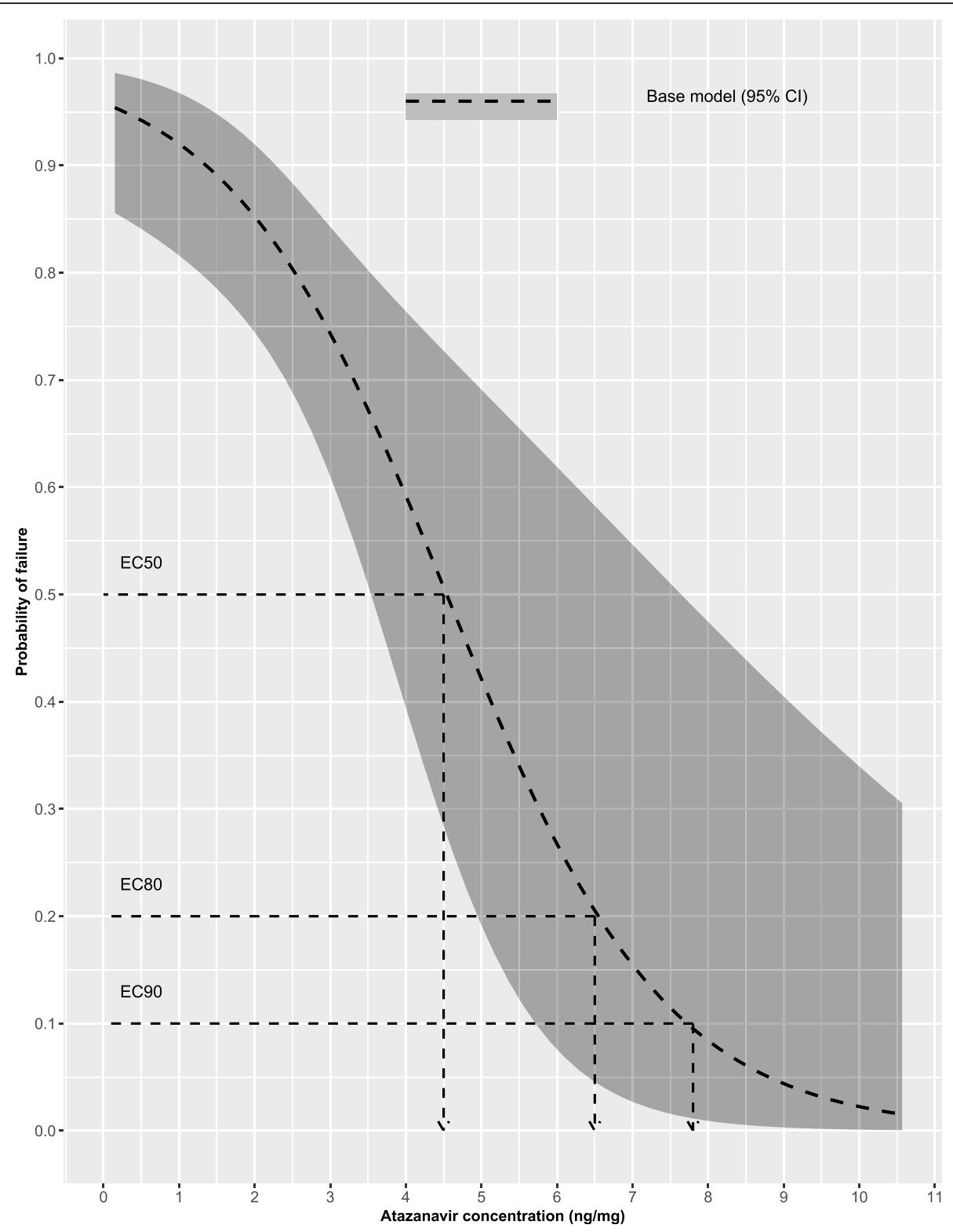

Fig. 1 Exposure-response curve presenting the baseline relationship between probability of failing to achieve viral load suppression (dashed line) including $95 \%$ confidence interval (shaded ribbon) and the simulated atazanavir concentrations in hair. The baseline $E C_{50}, E C_{80}$ and $E C_{90}$ values are illustrated on the plot (dashed arrows)

a $95 \%$ confidence interval of 1.8 to $7.5 \mathrm{ng} / \mathrm{mg}$ hair compared to that for participants with normal BMIfor-age. The average $E C_{50}$ for overweight participants was estimated to be approximately $5.5 \mathrm{ng} / \mathrm{mg}$ hair and a right-tailed $95 \%$ confidence interval with a lower limit of $3.5 \mathrm{ng} / \mathrm{mg}$ hair compared to that for participants with normal BMI-for-age. Figure 3 shows further the effect of normal BMI-for-age to the relationship between viral load and the simulated atazanavir concentrations in hair.

\section{Effect of caregiver status on $E C_{50}$ value}

We estimated that the $E C_{50}$ for participants who received care from mature caregivers ( $\geq 19$ years of age) approximately decreased to $3.8 \mathrm{ng} / \mathrm{mg}$ hair and $95 \%$ confidence interval of 2.3 to $6.4 \mathrm{ng} / \mathrm{mg}$ hair compared to that for participants receiving care from younger siblings (10 to 18 years). Figure 4 shows further the effect of receiving care from mature caregivers to the relationship between viral load and the simulated atazanavir concentrations in hair. 


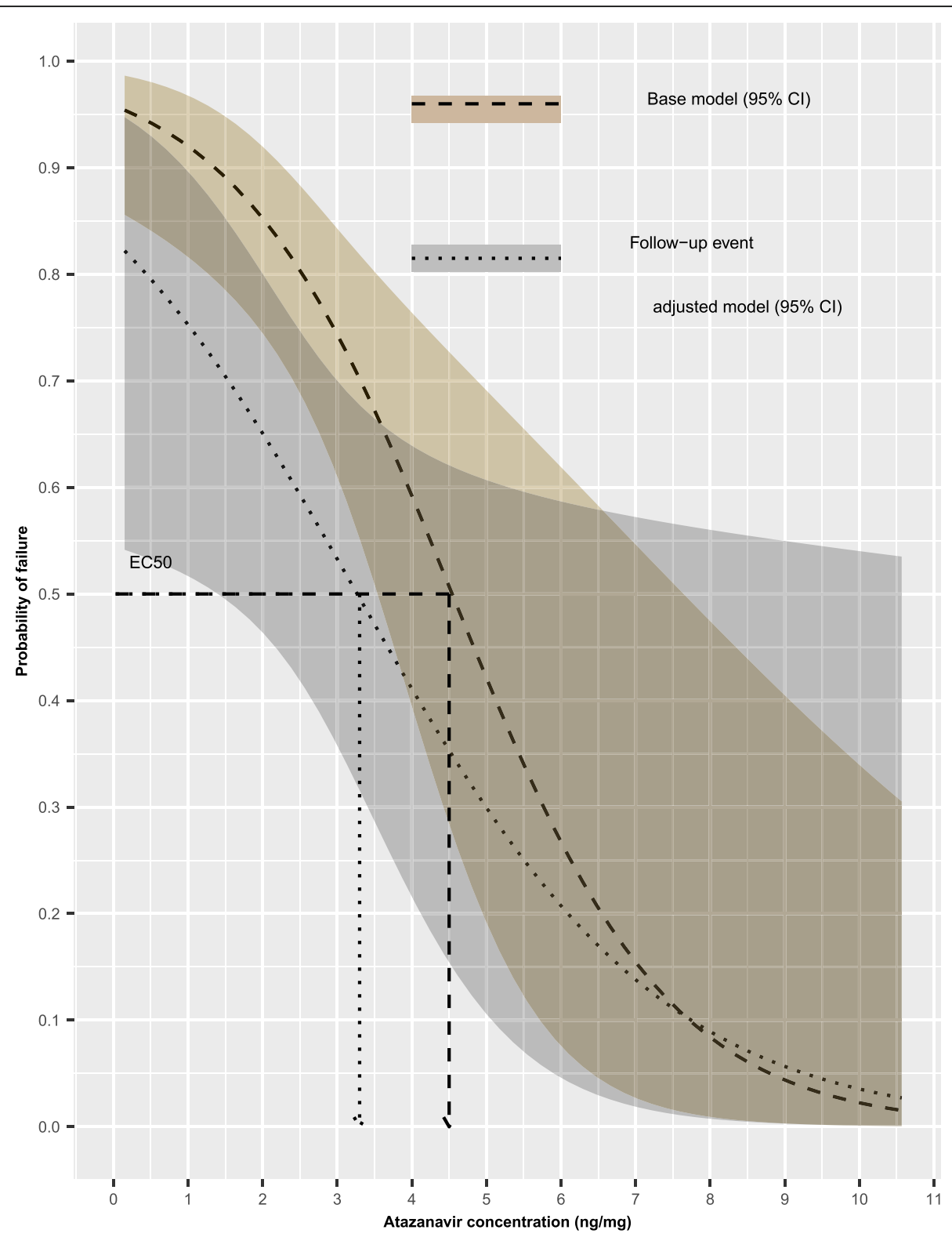

Fig. 2 Exposure-response curves presenting the baseline relationship between probability of failing to achieve viral load suppression (dashed line) including 95\% confidence interval (shaded ribbon) and the simulated atazanavir concentrations in hair, comparing with the effect of 50\% self-reported adherence to the relationship between probability of failing to achieve viral load suppression (dotted line) including $95 \%$ confidence interval (shaded ribbon) and the simulated atazanavir concentrations in hair. The baseline and $50 \%$ self-reported adherence adjusted $E C_{50}$ values are illustrated on the plot (dashed and dotted arrows, respectively)

\section{Effect of the follow-up event status on $E C_{50}$ value}

The $E C_{50}$ at the 3-months follow-up occasion was estimated to be an average of $3.3 \mathrm{ng} / \mathrm{mg}$ hair and righttailed 95\% confidence interval with a lower limit of 1.4 $\mathrm{ng} / \mathrm{mg}$ hair compared to that for the same participants at enrolment, irrespective of the study arm for these subjects. Figure 5 illustrates further the effect of the follow-up event to the relationship between viral load and the simulated atazanavir concentrations in hair.

\section{Effect of multiple covariates on $E C_{50}$ value}

The $E C_{50}$ for these adolescents at 3-months follow-up occasion, reporting adequate adherence, normal BMI-forage, and receiving care from mature caregivers concurrently was estimated to be approximately $2.6 \mathrm{ng} / \mathrm{mg}$ hair and left-tailed 95\% confidence interval with an upper limit of $5.5 \mathrm{ng} / \mathrm{mg}$ hair. Figure 6 illustrates further the effect of the multiple covariates on the relationship between viral load and the predicted atazanavir concentrations in hair. 


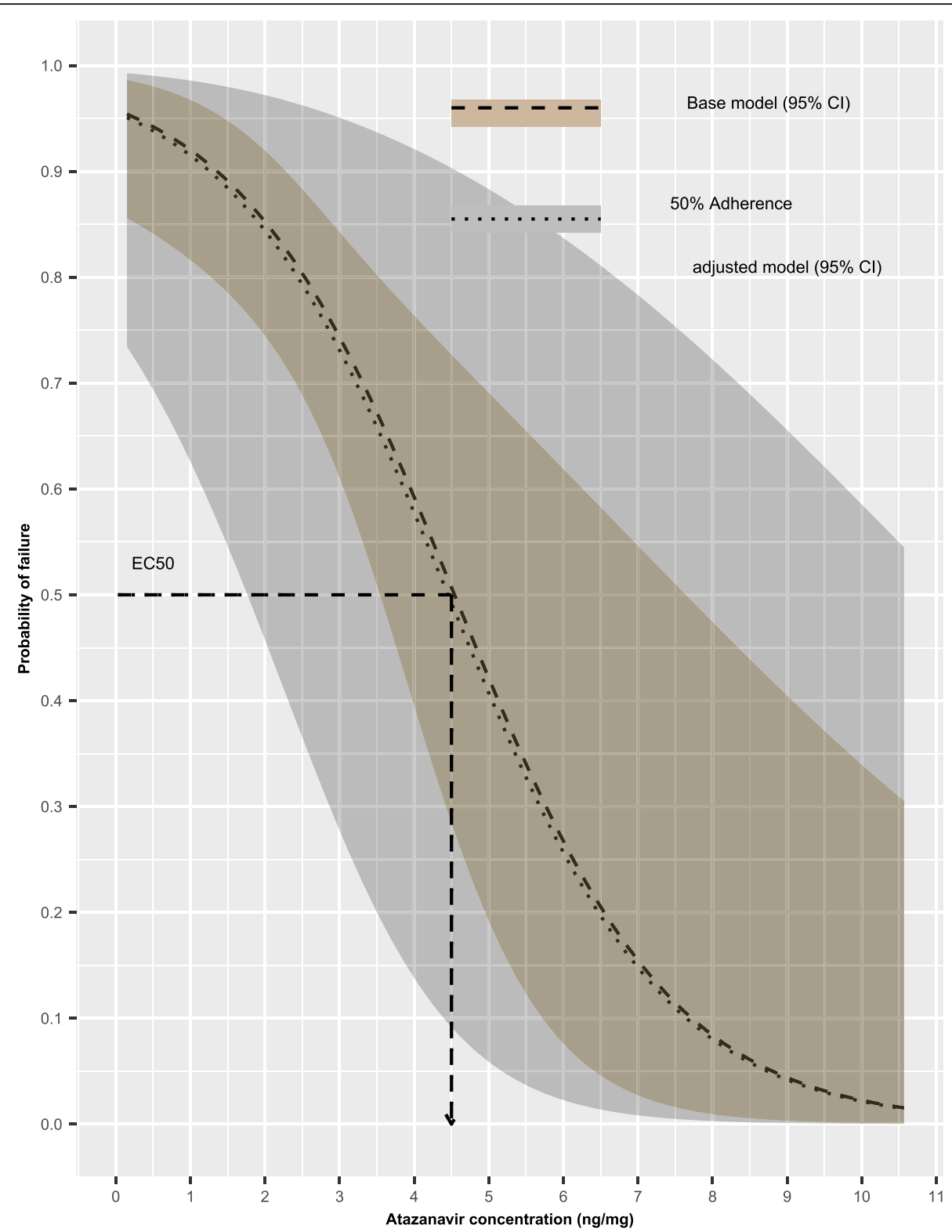

Fig. 3 Exposure-response curves presenting the baseline relationship between probability of failing to achieve viral load suppression (dashed line) including $95 \%$ confidence interval (shaded ribbon) and the simulated atazanavir concentrations in hair, comparing with the effect of normal BMI-for-age to the relationship between probability of failing to achieve viral load suppression (dotted line) including $95 \%$ confidence interval (shaded ribbon) and the simulated atazanavir concentrations in hair. The baseline and normal BMI-for-age adjusted $E C_{50}$ values are illustrated on the plot (dashed and dotted arrows, respectively)

\section{Statistical significance of covariates on atazanavir potency}

The 3-months follow-up occasion reduced the $E C_{50}$ value significantly at $5 \%$ level $(p<0.001)$, while all the other covariates which were included in the full model were not statistically significant at 5\% level. Additional information for the effect of individual covariate and the multiple covariates concurrently (full model) are presented in Table 1.

\section{Discussion}

We performed the population analysis to explore the relationship between atazanavir concentrations in hair and virologic response in adolescents failing 2nd line ART through the development of logistic regression models. The exposure of interest used in this work was simulated atazanavir concentrations based on our earlier work [21]. Some previous work showed that mathematical modelling can improve estimation of $E C_{50}$ when steady- 


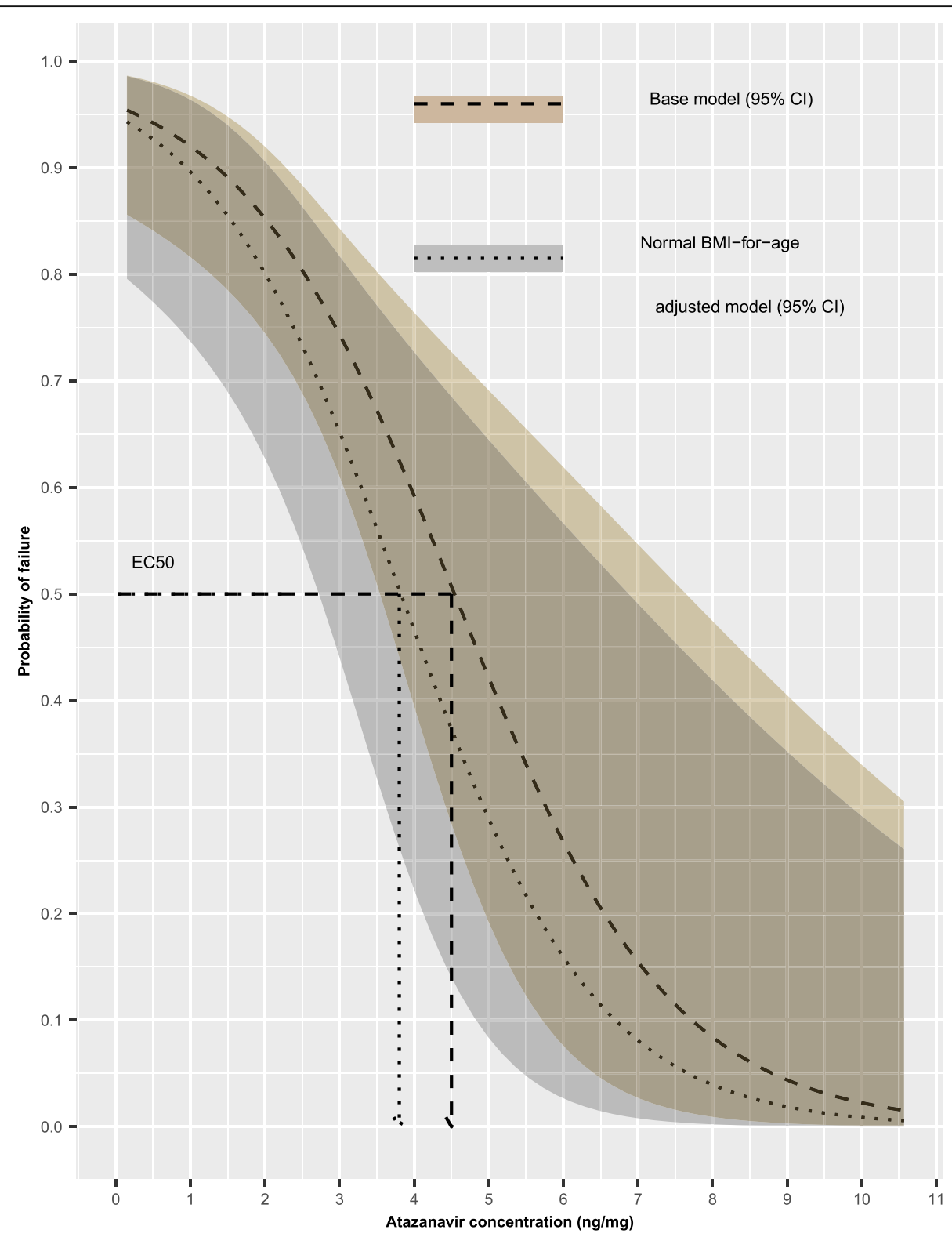

Fig. 4 Exposure-response curves presenting the baseline relationship between probability of failing to achieve viral load suppression (dashed line) including $95 \%$ confidence interval (shaded ribbon) and the simulated atazanavir concentrations in hair, comparing with the effect of mature care-giver status to the relationship between probability of failing to achieve viral load suppression (dotted line) including $95 \%$ confidence interval (shaded ribbon) and the simulated atazanavir concentrations in hair. The baseline and the mature care-giver status adjusted $E C_{50}$ values are illustrated on the plot (dashed and dotted arrows, respectively)

state simulations from a mathematical model are used, hence it will be possible to interpret previously obtained datasets again, and also to obtain accurate estimates of $E C_{50}$ even under circumstances where steady-state measurements are not experimentally feasible [22].

The choice of using atazanavir in the model does not have an association with the usefulness of drugs in clinical practise, but merely because they were feasibly available to the authors during the modelling work. Although the modelling results in this article add some knowledge for clinical practise, a particular interest was also to demonstrate a modelling framework usable to predict treatment outcome based on a measure of drug exposure obtained from hair. This approach can be extrapolated or adopted for use to any other drug being used in clinical practise. Drug exposure in hair has been found to predict treatment outcomes better than any standard measures known [23]. The fact that the PKPD model 


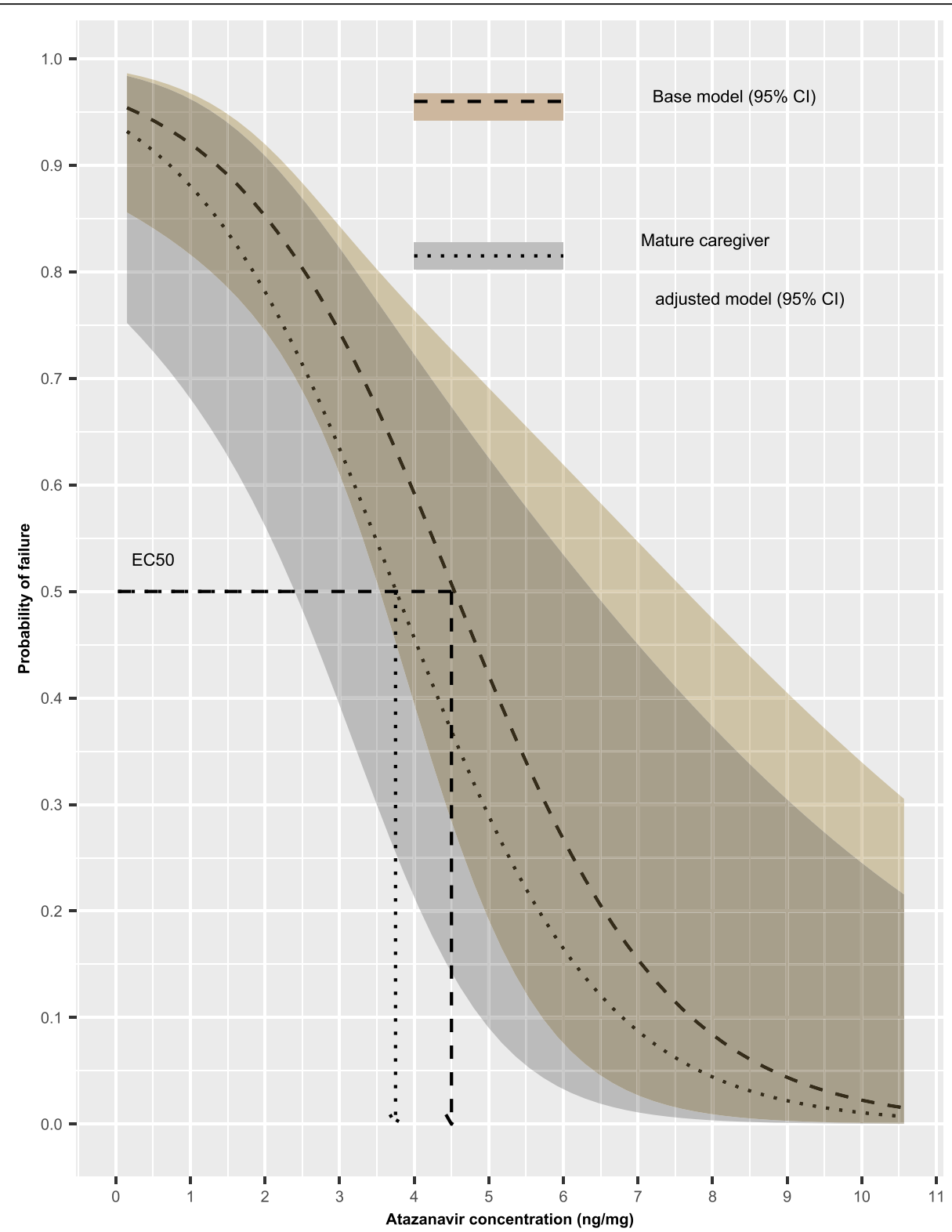

Fig. 5 Exposure-response curves presenting the baseline relationship between probability of failing to achieve viral load suppression (dashed line) including $95 \%$ confidence interval (shaded ribbon) and the simulated atazanavir concentrations in hair, comparing with the effect of the follow-up event to the relationship between probability of failing to achieve viral load suppression (dotted line) including $95 \%$ confidence interval (shaded ribbon) and the simulated atazanavir concentrations in hair. The baseline and the follow-up event adjusted $E C_{50}$ values are illustrated on the plot (dashed and dotted arrows, respectively)

has a dose component in its structural mechanism, a key component to determine the need for dose individualisation influenced the choice of the model framework. However, evaluation of dose-adjustment could not be performed in the current analysis because of the low sample size (such that $n<30$ for different categories of the BMI-for-age).

The study 3-months follow-up occasion was the only covariate that significantly improved potency of atazanavir in hair at $5 \%$ level of significance irrespective of the study arm. This could be that by taking part in the clinical trial, the participants had the knowledge that they were under study, possibly influencing positively their adherence to treatment and hence increasing their chances of treatment success. There was no blinding involved in the primary study during randomization of study participants to study arms [24], hence increasing the possibilities of bias. The covariates self-reported adherence, BMI-for-age, and participant caregiver status were included in the final model even though they were 


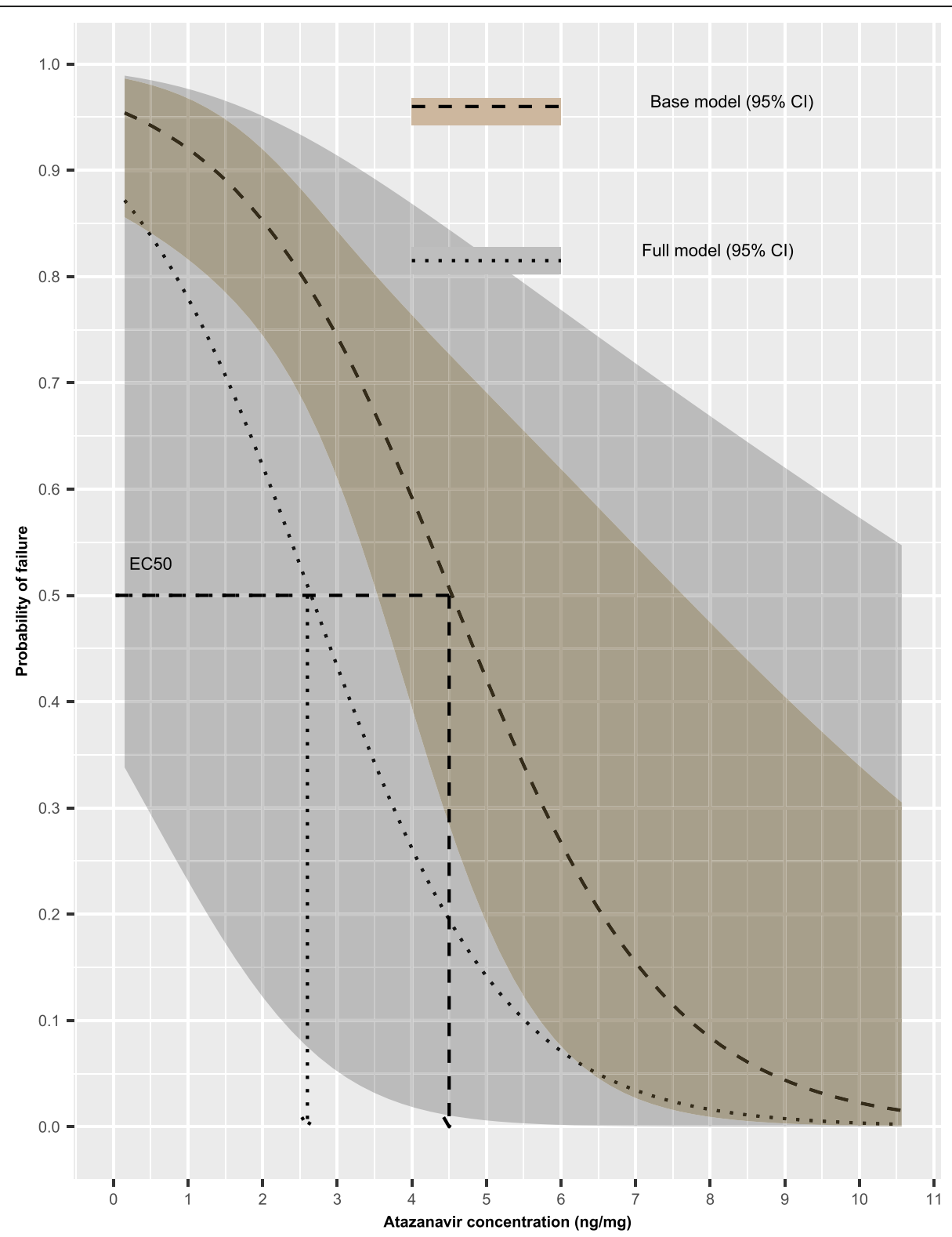

Fig. 6 Exposure-response curves presenting the baseline relationship between probability of failing to achieve viral load suppression (dashed line) including $95 \%$ confidence interval (shaded ribbon) and the simulated atazanavir concentrations in hair, comparing with the effect of the 3months follow-up occasion, reporting adequate adherence, having normal BMl-for-age, and receiving care from mature caregivers concurrently (dotted line) including 95\% confidence interval (shaded ribbon) and the simulated atazanavir concentrations in hair. The baseline and the followup event adjusted $E C_{50}$ values are illustrated on the plot (dashed and dotted arrows, respectively)

not significant at $5 \%$ level of significance, but because they reduced the $E C_{50}$ of atazanavir concentrations in hair clinically significantly. Hence the individual effect of these covariates needs further evaluation in the future studies.

The simulations performed show that probabilities of antiretroviral treatment success among those reporting $50 \%$ or $100 \%$ self-reported adherence is the same. However participants with $50 \%$ self-reported adherence had wider confidence intervals compared to participants with
$100 \%$ self-reported adherence which accurately predicted treatment success the same as atazanavir concentration in hair. This finding supports earlier findings which showed that protease inhibitor levels in hair predict virologic treatment outcome better than self-reported adherence which provide information on exposure to a drug of interest over a short period and is affected by recall bias [19, 20, 25].

Participants with normal BMI-for-age improved potency of atazanavir in hair while being either overweight 
Table 1 Covariate effects on $E C_{50}$ values

\begin{tabular}{lll}
\hline Adjusted $E C_{\mathbf{5 0}}$ value & $\begin{array}{l}\text { Estimated } E C_{\mathbf{5 0}} \text { in } \mathbf{~ g / m g} \text { of atazanavir in hair } \\
\text { (95\% Confidence Interval) }\end{array}$ & $\boldsymbol{p}$-value \\
\hline$E C_{50}:$ Base model & $4.5(3.5-7.6)$ & (NA -reference model) \\
$E C_{50}:$ Follow-up event & $3.3(1.4-\square)$ & $<0.001$ \\
$E C_{50}: 100 \%$ Self-reported adherence & $4.5(3.5-7.6)$ & 0.304 \\
$E C_{50}: 50 \%$ Self-reported adherence & $4.5(1.8-\square)$ & 0.304 \\
$E C_{50}:$ Normal BMl-for-age participants & $3.8(2.7-6.8)$ & 0.927 \\
$E C_{50}:$ Overweight participants & $3.5(1.8-7.5)$ & 0.927 \\
$E C_{50}:$ Underweight participants & $5.5(3.5-\square)$ & 0.927 \\
$E C_{50}:$ Mature care-givers & $3.8(2.3-6.4)$ & 0.636 \\
$E C_{50}:$ Full model & $2.4(\square-5.5)$ & 0.919
\end{tabular}

or underweight reduced potency during multivariate analysis. This also concurs with earlier findings which reported that normal to higher BMI is associated with improved immunological health compared to lower BMI [26-28]. Participants receiving care from mature caregivers have increased chances of viral load suppression, again supporting findings from previous studies. Their findings highlighted the effect of caregiver maturity on psychological distress to the complexity of perinatal HIV-infection, chronic HIV disease and lifelong ART in adolescents $[29,30]$.

The $E C_{50}$ of atazanavir in hair for adolescents was estimated to be $4.5 \mathrm{ng} / \mathrm{mg}$ hair before adjusting for covariates effect. However the $E C_{50}$ of atazanavir in hair was optimally reduced to $2.4 \mathrm{ng} / \mathrm{mg}$ hair when the model was simulated using participant specific variables that had potential to reduce the value. The model-based optimal estimate of the $E C_{50}$ of atazanavir in hair concurs with the result reported in the primary study which proposed a cut-off of $2.35 \mathrm{ng} / \mathrm{mg}$, the lower quartile of the observed atazanavir concentration in hair among participants who achieved viral load suppression at 3-months follow-up [18].

To the best of our knowledge, this is the first study to apply mathematical modelling to establish cut-off points for antiretroviral drugs measured in hair which are associated with certain levels of the probability of viral load suppression. Some covariates were reported in both the bivariate and multivariate models on the basis of their clinical significance even though they were not statistically significant. In this study, our $95 \%$ confidence intervals of parameter estimates may look higher, which can be attributed to the fact that both the PK [21] and the PKPD modelling was based on a limited and small sample size $(n=50)$. Additionally, most of the simulated atazanavir in hair concentrations were below the $E C_{50}$, $E C_{80}$ and $E C_{90}$ values based on the model projections which is a sign of model over-prediction, something which could have been influenced again by the limited sample sizes It is important both future primary and modelling studies which are going to be conducted to collect a wide range factors that influence exposureresponse and also use a large sample size.

\section{Conclusion}

In conclusion, atazanavir in the hair in the range 2.4 to $4.5 \mathrm{ng} / \mathrm{mg}$ is likely associated with at least $50 \%$ chances of HIV suppression. Hair drug concentration predicts chances of viral suppression more accurately when compared to self-reported adherence. Direct monitoring of dose ingestion is recommend for adolescents failing 2nd line ART to improve chances of viral suppression. Also specialised health-care interventions are recommended for adolescents on ART whose caregivers are immature to improve their chances of viral suppression. Doseadjustment require to be evaluated further especially for underweight or overweight participants using PKPD modelling.

\section{Acknowledgements}

The authors would like to acknowledge all the members involved in the primary study including the study participants, and some member of the University of California San Francisco (United States of America) which was involved in the lab analysis of the hair assays and producing the drug concentration data we used. We also extend our acknowledgements to the University of Cape Town (South Africa) for providing a computing platform with the NONMEM software.

\section{Authors' contributions}

B.N. S.P.Z, and S. R were involved in model development and validation plus the statistical interpretation of model results. T.D.C and C. N provided the data of the primary study plus the clinical or pharmacological interpretation and review of model results. B. N, S.P.Z and T.D.C were involved in writing the manuscript. All the authors have read and approved the manuscript.

\section{Funding}

The first author of this article was awarded with a doctorate scholarship by Letten Foundation Research Centre, Zimbabwe. This research was

commissioned by the National Institute for Health Research, using Official Development Assistance (ODA) funding 16/136/33. The views expressed in this publication are those of the authors only and the funders did not play any role in the design of the study; collection, analysis, interpretation of data, and in writing the manuscript. 


\section{Availability of data and materials}

The primary study did not publish the data to the public, however the data can be available upon request and approval from the principal investigators of the primary study. The principle investigator of the primary study was Tariro Dianah Chawana, and can be contacted on email (tdchawana@gmail.com).

\section{Declarations}

\section{Ethics approval and consent to participate}

Consent to participate in the study was waived by the ethical review committees. The principal investigator of the primary study provided an official written consent this study to use their data for secondary analysis, which was also used in obtaining approval to use secondary data from the institutional and national ethical review committees [Joint Research Ethics Committee (JREC/101/18) and Medical Research Council of Zimbabwe (MRCZ/A/2301) respectively].

\section{Consent for publication}

N/A

\section{Competing interests}

The authors declare that there is no conflict of interest.

\section{Author details}

${ }^{1}$ Department of Community Medicine, University of Zimbabwe College of Health Sciences, Mazowe Street, Parirenyatwa Complex, P. O Box A178 Avondale, Harare, Zimbabwe. ${ }^{2}$ Department of Clinical Pharmacology, Stellenbosch University, Private Bag X1, Matieland, Stellenbosch 7602, South Africa. ${ }^{3}$ Department of Clinical Pharmacology, University of Zimbabwe College of Health Sciences, Mazowe Street, Parirenyatwa Complex, P. O Box A178 Avondale, Harare, Zimbabwe.

\section{Received: 1 December 2020 Accepted: 4 May 2021}

\section{Published online: 24 May 2021}

\section{References}

1. Atkinson AJ, Lalonde R. Introduction of quantitative methods in pharmacology and clinical pharmacology: a historical overview. Clininacal Pharmacol Ther. 2007;82(1):3-6. https://doi.org/10.1038/sj.clpt. 6100248.

2. Cox DR, Snell EJ. Analysis of Binary Data [Internet]. [cited 2019 Aug 23]. Available from: https://www.crcpress.com/Analysis-of-Binary-Data/Cox-Snell/ p/book/9780412306204

3. Lu W, Bailey JM. Reliability of pharmacodynamic analysis by logistic regression: a computer simulation study. Anesthesiology. 2000;92(4):985-92. https://doi.org/10.1097/00000542-200004000-00015.

4. Laskowski R. Some good reasons to ban the use of NOEC, LOEC and related concepts in ecotoxicology. Oikos. 1995;73(1):140-4. https://doi.org/10.2307/3 545738.

5. Stadnicka-Michalak J. A validated algorithm for selecting non-toxic chemical concentrations. ALTEX. 2017;35(1):37-50. https://doi.org/10.14573/altex.1 701231.

6. Tanaka Y, Nakamura K, Yokomizo H. Relative robustness of NOEC and ECX against large uncertainties in data. PLoS One. 2018;13(11):e0206901. https:// doi.org/10.1371/journal.pone.0206901.

7. Fox DR. Is the ecx a legitimate surrogate for a noec? Integr Environ Assess Manag. 2009;5(2):351-3. https://doi.org/10.1897/1551-3793-5.3.351.

8. Meddings JB, Scott RB, Fick GH. Analysis and comparison of sigmoidal curves: application to dose-response data. Am J Physiol-Gastrointest Liver Physiol. 1989;257(6):G982-9. https://doi.org/10.1152/ajpgi.1989.2 57.6.G982.

9. Hosmer DWJr, Lemeshow S, Susanne M. Applied Logistic Regression, 3rd Edition [Internet]. [cited 2019 Aug 23]. Available from: https://www. wiley.com/en-zw/Applied+Logistic+Regression\%2C+3rd+Edition-p-97804 70582473

10. Parellada J, Guinea M. Flavonoid inhibitors of trypsin and leucine aminopeptidase: a proposed mathematical model for IC50 estimation. J Nat Prod. 1995;58(6):823-9. https://doi.org/10.1021/np50120a001.
11. Soothill JS, Ward R, Girling AJ. The IC50: an exactly defined measure of antibiotic sensitivity. J Antimicrob Chemother. 1992;29(2):137-9. https://doi. org/10.1093/jac/29.2.137.

12. Calderone V, Martinotti E. Intrinsic activity and EC50: the simplest tools for the evaluation of the dissociation constant of a partial agonist. J Pharmacol Toxicol Methods. 1998;40(4):207-10. https://doi.org/10.1016/S1056-871 9(99)00007-6.

13. Lin Z, Zhong $P$, Yin $K$, Zhao D, Wang L, Yu H. Use of the IC50 for predicting joint toxic effects of mixtures. Bull Environ Contam Toxicol. 2004;72(3):571-8. https://doi.org/10.1007/s00128-004-0282-7.

14. Jozwiak K, Moaddel R, Yamaguchi R, Ravichandran S, Collins JR, Wainer IW. Qualitative assessment of IC50 values of inhibitors of the neuronal nicotinic acetylcholine receptor using a single chromatographic experiment and multivariate cluster analysis. J Chromatogr B Analyt Technol Biomed Life Sci. 2005;819(1):169-74. https://doi.org/10.1016/j. jchromb.2005.01.043.

15. Clothier R, Dierickx P, Lakhanisky T, Fabre M, Betanzos M, Curren R, et al. A database of IC50 values and principal component analysis of results from six basal cytotoxicity assays, for use in the modelling of the in vivo and in vitro data of the EU ACuteTox project. Altern Lab Anim ATLA. 2008;36(5):503-19. https://doi.org/10.1177/026119290803 600509.

16. Burt HJ, Galetin A, Houston JB. IC50-based approaches as an alternative method for assessment of time-dependent inhibition of CYP3A4. Xenobiotica Fate Foreign Compd Biol Syst. 2010;40(5):331-43. https://doi. org/10.3109/00498251003698555

17. Vanewijk PH, Hoekstra JA. Calculation of the EC50 and its confidence interval when subtoxic stimulus is present. Ecotoxicol Environ Saf. 1993; 25(1):25-32. https://doi.org/10.1006/eesa.1993.1003.

18. Chawana TD, Gandhi M, Nathoo K, Ngara B, Louie A, Horng H, et al. Defining a cut-off for atazanavir in hair samples associated with virological failure among adolescents failing second-line antiretroviral treatment. J Acquir Immune Defic Syndr. 2017;76(1):55-9. https://doi.org/10.1097/QAl. 0000000000001452

19. Gandhi M, Ameli N, Bacchetti P, Gange SJ, Anastos K, Levine A, et al. Protease inhibitor levels in hair samples strongly predict Virologic responses to HIV treatment. AIDS Lond Engl. 2009;23(4):471-8. https://doi.org/10.1097/ QAD.0b013e328325a4a9.

20. Gandhi M, Ameli N, Bacchetti P, Anastos K, Gange SJ, Minkoff H, et al. Atazanavir concentration in hair is the strongest predictor of outcomes on antiretroviral therapy. Clin Infect Dis Off Publ Infect Dis Soc Am. 2011;52(10): 1267-75. https://doi.org/10.1093/cid/cir131.

21. Ngara B, Zvada S, Chawana TD, Stray-Pedersen B, Nhachi CFB, Rusakaniko S. A population pharmacokinetic model is beneficial in quantifying hair concentrations of ritonavir-boosted atazanavir: a study of HIV-infected Zimbabwean adolescents. BMC Pharmacol Toxicol. 2020;21(1):58. https://doi. org/10.1186/s40360-020-00437-y.

22. Nyman E, Lindgren I, Lövfors W, Lundengård K, Cervin I, Sjöström TA, et al. Mathematical modeling improves EC50 estimations from classical dose-response curves. FEBS J. 2015;282(5):951-62. https://doi.org/1 0.1111/febs.13194.

23. Müller AD, Jaspan HB, Myer L, Lewis Hunter A, Harling G, Bekker LG, et al. Standard measures are inadequate to monitor pediatric adherence in a resource-limited setting. AIDS Behav. 2011;15(2):422-31. https://doi.org/10.1 007/s10461-010-9825-6.

24. Chawana TD, Katzenstein D, Nathoo K, Ngara B, CFB N. Evaluating an enhanced adherence intervention among HIV positive adolescents failing atazanavir/ritonavir-based second line antiretroviral treatment at a public health clinic. J AIDS HIV Res. 2017;9(1):17-30. https://doi.org/10.5897/JAHR2 016.0406.

25. Gandhi M, Greenblatt RM. Hair it is: the long and short of monitoring antiretroviral treatment. Ann Intern Med. 2002;137(8):696-7. https://doi.org/1 0.7326/0003-4819-137-8-200210150-00016.

26. Blashill AJ, Mayer KH, Crane HM, Grasso C, Safren SA. Body mass index, immune status and Virological control in HIV-infected men who have sex with men. J Int Assoc Provid AIDS Care. 2013;12(5):319-24. https://doi.org/1 $0.1177 / 2325957413488182$

27. Li X, Ding H, Geng W, Liu J, Jiang Y, Xu J, et al. Predictive effects of body mass index on immune reconstitution among HIV-infected HAART users in China. BMC Infect Dis. 2019;19(1):373. https://doi.org/10.1186/ s12879-019-3991-6. 
28. Martinez SS, Campa A, Bussmann H, Moyo S, Makhema J, Huffman FG, et al. Effect of BMI and fat mass on HIV disease progression in HIV-infected, antiretroviral treatment-naïve adults in Botswana. Br J Nutr. 2016;115(12): 2114-21. https://doi.org/10.1017/S0007114516001409.

29. Nasuuna E, Kigozi J, Muwanguzi PA, Babirye J, Kiwala L, Muganzi A, et al. Challenges faced by caregivers of virally non-suppressed children on the intensive adherence counselling program in Uganda: a qualitative study. BMC Health Serv Res. 2019;19(1):150. https://doi.org/1 0.1186/s12913-019-3963-y.

30. Marhefka SL, Tepper VJ, Brown JL, Farley JJ. Caregiver psychosocial characteristics and children's adherence to antiretroviral therapy. AIDS Patient Care STDs. 2006;20(6):429-37. https://doi.org/10.1089/apc.2 006.20.429.

\section{Publisher's Note}

Springer Nature remains neutral with regard to jurisdictional claims in published maps and institutional affiliations.

Ready to submit your research? Choose BMC and benefit from:

- fast, convenient online submission

- thorough peer review by experienced researchers in your field

- rapid publication on acceptance

- support for research data, including large and complex data types

- gold Open Access which fosters wider collaboration and increased citations

- maximum visibility for your research: over $100 \mathrm{M}$ website views per year

At BMC, research is always in progress.

Learn more biomedcentral.com/submissions 